any habit-good as well as bad-it will grow upon you. If of a practical turn, you will work by experience and observation; if of a scientific turn, you will work by experiment. Both have their value; and even if you only take up the rôle of an overturner of false doctrine, or even a critic of true doctrine, you will all have your use, as Marcus Aurelius says: "Men co-operate after different fashions, and even those co-operate abundantly who find fault with what happens, and those who try to oppose it and to hinder it, for the universe hath need even of such men as these."

One word of warning. The simple treatment of a wound with water dressing was, we now know, imperfect; still the majority were satisfied. Accidents, local and constitutional, were smoothed off and excused by the too common phrase, We had done our best. Let us take care that we do not fall into this error with regard to our present work. As you work, be sure to fight against any temptation which may encourage you to suppose that our knowledge is now perfect. Perfection is not of this world. Is it too much to ask for encouragement for individual work? Some years ago I tried to show that our extra-mural school-a most important factor in our system of medical education-owes very much of its success to the encouragement which is given to the individuality of its teachers, everyone of whom haschosen that subject to which he has devoted special attention. May I now say a word for the individuality of the taugbt? May I plead toleration and assistance for the man who desires to develop his mental individuality, who desires to concentrate his mind on some special piece of work? There is need for someone to speak out, to "use plain discourse," and to say, that if the public are to require of every candidate for any public duty a univessal knowledge, the acquiring of which needs all his energies, then any power which he may originally have had of doing some special work-his individuality, his physical and mental personality - will be crushed out of him. Even our schoolboys are nowadays required to pas; a certain standard, the examination system is in full force even in our infant schools. Would we not have more "lucidity" if the growth of our intellects was less fettered, simply directed, rather than pruned and trimmed, ordered to do this, forbidden to do that? Any unnecessary interference with the taught at once tells on the visefulness of the teacher. What opportunity have our schoolmasters to develop any special talent in their pupil when their energies are fully occupied in polishing all their material-good, bad, and indifferent-to one standard? The schoolmaster seems now to have little pleasure in life, he is a mill-horse working round a pivot, a mill-wheel supplied with water to do one thing-namely, polish boys. Let the pablic see that they take care that those to whom they entrust the education of the medical practitioner are allowed some scope for their imagination, some opportunity to develop the individuality of their students. The essentially evil feature of centralisation is its want of personality. Our medical schools still possess some personality; it will be a bad day when that is interfered with. This school to which we happily belong, will lose much of its brightness, will be hampered in its usefulnes, if its teachers are compelled to degenerate into polishing machines. May I ever have before me, as an important part of my duty, the encouragement of the individuality of my students. May I be enabled ever to remember that I am dealing with men, each one of whom has some special ability, every one of whom has some special work. May I endeavour, as far as in me lies, to search out that special ability, to encourage and to direct that special work. Give me your help in the future as you have al ways done in the past; without your confidence I can do little, with it I will endeavour, by devotion to my duties as your teacher, to maintain the reputation of this school for honest work. Working together, let us day by day feel that something has been attempted, something has been done, and at the end of the session we will be able to look back with an inward feeling that, while far from what it should have been, some advance has been made, some problem has been solved. Remember tbat to everyone present a talent has been given. Let him look to it that he uses that talent aright.

A FeVER-STrRCKeN CREw. - Lloyd's agent at Norfolk, Va., telegraphs that the Marie Anne, French brig from St. Domingo to Harre, had been towed into Norfolk, Va., by the Spanish steamer Bellver, with only three men on board, all the others, including the captain, having died of yellow ferer.
ON

THE ACTION OF THE SALTS OF SODITI, AMMONIUM, AND POTASSIUMI.

BY SYDNEY RINGER, M.D., AND

HARRINGTON SAINSBURY, M.D.

THE difficulties attending the observation of the action of drugs clinically result obviously from the complexity of the phenomena presented; in like manner, the pharmacologikt, so long as his investigations relate to the animal organin in its entirety, has essentially to deal with the complex. Inference under these circumstances is correspondingly difficult. If to avoid this source of error our observations be restricted to a portion of the organism, it is clear that our inferences gain in exactitude in exact proportion to the simplification effected. 'The difficulty now lies in the appli. cability of inferences so gained when we pass to conditions no longer simple. It was with this difficulty clearly in rierr that the experiments, the results of which will now be shortly discussed, were undertaken.

The ventricle of the frog's heart was the test tissue selected. Through such ventricle of a heart isolated from the body an artificial circulation was maintained, whilst by means of a suitable apparatus (Roy's tonometer) the contractions were registered on a revolving blackened cylinder. The particular drug used was added to the circulating fluid. We were thas able to compare the working of the drugoed and undrugoed ventricle under conditions, artificial it is true, but definite and under control.

The structure and function of the tissue so selected are essentially twofold: ganglionic structures aud muscular fibres on the one side; rhythmic contractility on the oheri. e., rhythm and contractility. The nervous nature of rbrthm may be debatable; but that contractility is muscular is certain.

On such rhythmically contracting heart the action of the salts of potassium, sodium, and aumonium is briefly as follows :-

All tbree arrest the ventricle in diastole; they contrast, however, in the mode of arrest. Thus, as to their action on rhythm: Potassium salts tend markedly to arrest or suspend the spontaneous contractions, whilst yet the heart may be proved to be contractile by suitable excitation. Ammonium salts show no such tendency; the heart beats, often with an increased frequency, up to the very end-i. e., as long as contractility persists. Sodium salts fit in between, but come very much nearer ammonium than potassium salts, their action on rhythm being very slight.

As to their action on contractility, we have, on the one hand, potassium and ammonium salts acting with almost equal intensity; on the other hand, a wide gap interrening, sodium salts showing but feeble action.

One other point of contrast may be mentioned, it refers to the effect of continuous faradisation. This rapidly loses its power to excite the ventricle to cuntraction when a potissium salt is used; not so for the other bases, and the very slinth and somewhat inconstant effect for ammonium and sodium salts contrasts strongly with the uniform and marlied effect of potassium salts.

Restricting ourselves to these broad lines ${ }^{1}$ of contrist, some important points come out:-

First, an important fact-namely, that throughout tle salt of potassium, sodium, ammonium, the potassium, sodium and ammonium elements are traceable. Indeed, in these experiments they appeared to rule the effect. Quite recently, ${ }^{-}$in leading article, reference is made to experiments on unstrineil muscular tissue by Nothnagel; the same result was observed here, the potassium and sodium action appearing to be in dependent of the combination of these bases. These exrert. ments, then, on isolated tissues would be confirmatory of the older statement by Guttmann with refereuce to putassiun salts-namely, that they are all exactly alike in the cins raster and intensity of their action. ${ }^{3}$ The results, howerey.

1 For further details consult papers by the authors in the $y e$ Chirurgical Transactions (vol. lxv.), and in the Practitioner (Aut.

2 THE LANCET, July, 188

3 Wood's Therapeuties, third edition, p. 484 
probably represent but a partial truth. The completer stateiment probably should be that elements and groups of elements retain more or less of their individuality throughout their combinations, and this would surely apply to either side of a salt-the base and the acid. The value of such statement would bo as a help towards classification.

Sext, that under these simple conditions specified, a certain relation between potassium, sodium, and ammonium salts is manifest. Potassium standing first as most poisonous and threatening in two directions; ammonium coming next, its action being restricted to destruction of contractility; sodium coming last and ranking as but very slightly poisonous comparatively with either. These experiments, indeel, would make prtassium salts some fourteen or fifteen times as poisonous as sodium salts. Is the conclusion not rarranted that in their action on the muscular tissue of the rentricle, and on its intrinsic nervous apparatus, these salts will maintain a like relation, even though the conditions be the more complex and indefinite ones of the organism in its entirety? It is not that one would exclude action on the nerve centres, vagus, \&c., from the effect witnessed on the entire organism, but that one would specify one from among the many fastors in the equation. This relation of the salts of potassium, sodium, and ammonium has however been tested on other tissues, and found to hold-e.g., on the nervous system. ${ }^{4}$ The results also with the entire organism show that whilst potassium salts are very poisonous, sodium salts can scarcely be made to kill.

Insistence has already been made in various quarters on the use of sodium and ammonium salts in preference to potassium salts; more especially has this been urged for the bromides. ${ }^{5}$ (The bromide of sodium has been rather largely used in America.) Clinical evidence must obviously give the final judgment; but have we not here clear indication as to the lines on which clinical investigation should be pursued?-the suggestion being that salts of sodium should throughout be substituted for those of potassium and ammonium, till clinical evidence decide that the action of one or other of these bases is required in the particular case under treatment? This suggestion, then, is based not only on the results of experiments with the entire organism, but also on these more definite results gained from experiments on isolated tissues.

It may be added that both at the Children's Hospital, Great Ormond-street, through the kindness of Dr. Barlow, and at the Western General Dispensary, Marylebone, we have had the opportunity of trying the chlorate of sodium ${ }^{6}$ in cases of stomatitis, with ulceration along the edges of the gums, but few cases up to the present have been collected. So far, however, the evidence in its favour is every bit as unequivocal as it is for potassium chlorate, which might be said to be one of the show drugs in therapeutics. Two of the cases gave the best kind of evidence obtainable; they were, namely, cases of relapse, and were cured by pushing the drug.

\section{NOTE ON THE \\ CLINICAL CHARACTERS OF TUBERCLE IN BONE.}

BY WM. SCOVELL SAVORY, F.R.S, SURGEON TO ST. BARTHOLOMEW'S HOSPITAL.

IT is curious on reflection to see how many striking points of analogy there are between the progress and effects of tubercle in lung and in bone. In the first place the cancellous texture of bone, which is the seat of tubercle, resembles broxdly in physical characters the parenchyma of lung. A section of cancellous bone and a section of dried lung lave to the naked eye a very general resemblance. The structure of both is a,tly described as sponge-like, and this resemblance is drawn more closely when a mass of yellow tubercle occupies the substance of each. In both cases the

* Pinger and Murrell : Journal of Anatomy, vol. xii., p. 71 . For further reference see also Wood's Therapeutics; articles Potassium Salt: also Phys. Action of Sodium and Ammonium Bromides. Third tition, 1981.

Ste Wood's Therapentics, Bromide of Sodium. Also paper on Epileysy with Cardiae Complications, by W. A. Hollis, M.D., Practitioner, rol. xxii., p. 81.

. Through the kindness of Mr. Martindale we were provided with a purespecimen of this salt. spongy texture appears to be filled up and rendered solid by the infiltration of the caseous deposit. Then, too, the resemblance further appears in the halo of inflammation or increassd vascularity of varying width which so often surrounds the mass. Still further is the likeness shown in the mode in which the tubercle degenerates. The included tresue is broken down and destroyed until, either by the escape or disappearance of the tubercle, a cavity is left in the cancellous bone corresponding very remarkably to a vomica in the lung. Furthermore, the likeness is extended by the relation of cancellous bone to a neighbouring joint and the relation of lung substance to the plenra. Just as pleurisy is so often set up by the disturbance of tubercle in the lung, so synovitis is often provoked by the disturbance of tubercle in adjacent bone; and just as empyema is sometimes produced by the perforation of the lung-wall and the escape of matter into the pleural cavity, so suppuration in a joint, which is too often destructive, is due to the per. foration of the articular wall of bone and the escape of matter into the synovial cavity. In either case urgent symptoms are apt to supervene suddenly on comparatively latent mischief.

Then, I think, the variable progress and effect of tuherc!e in the lung are oftentimes repeated with singular resemblance in bone. This first struck me many years ago in studying the graphic picture which Dr. Latham drew of the varinus forms of phthisis in his masterly Lectures on Clinical Medicine, which, by the way, have been happily reproduced by the Sydenham Society under the editorship of Dr. Martin. Just as in lung, so in bone; the history of tubercle is sometimes that of a single formation, which passes steadily, with more or less rapidity, to destruction; sometimes that of several smaller ones simultaneous'y ; sometimes, though this more rarely, that of a number of successive formations which pass through their stages one after another, leading in this way to a gradually extending destruction of osseous tissue. So, again, and in this I think the resemblance is most marked of all, there are in tubercle in bone phenomena very exactly corresponding to what Dr. Latham in the lung, and in the cervical glands as a more obvious illustration, has described as cases of mixed and unmixed phthisis. In one class, during the changes which tubercle, after its formation, is prone to underyo, there is only what may be called a necessary amount of inflammation excited in the surrounding texture, such as is just sufficient to accomplish the result of softening and expulsion, and which subsides as soon as that is effected. This Dr. Latham called the specific limit of the disease. In another class the inflammation provoked spreads widely and deeply beyond this, and becomes much more severe and extensive than is needful for the mere elimination of the tuberculous matter. In short, Dr. Latham's sketch might have been drawn from a study of tubercle in the head of the femur or tibia or in the tarsus or vertebræ.

Witbin the whole range of pathology I know no better illustration of the value of extended study, or rather of the great loss from limited views which must come of ton special observation. For the study of tubercle, if the difficulty would be adequately grasped, must be carried on not only throughout the whole fields of medicine and of surgery, but here, at all events, there can and ought to be no boundary between them. For the largest purpose, the land to be explored must be common to both.

Brook-street, W.

\section{ANOTHER NEW TEST FOR ALBUMEN.}

\section{BY GEORGE JOHNSON, M.D., F.R.S.,}

PROFESSOR OF CLINICAL MEDICINE AND SENIOR PHYSICIAN TO KING'S COLLEGE HOSPITAL.

My son, G. Stillingfleet Juhnson, in a paper published in the Journal of the Chemicxl Society (August, 1874) describes some compounds of albumen with the mineral acids, and gives a table showing the action of various chemical reagents in causing coagulation in solutions of these albumen compounds. He found that only two reagents besides the mineral acids cause the coagulation of albumen in solutions of all its acid compounds-namely, baric chloride and picric acid, -and he suggested to me that the latter of these two substances might be found a useful test for albumen in the urine; for while the baric chloride could not be added to normal urine without being precipitated by many of its 